\title{
Volume 103 Issue 4, December 2021
}

\section{Kimon P. Valavanis ${ }^{1}$}

Published online: 30 November 2021

(c) The Author(s), under exclusive licence to Springer Nature B.V. 2021

\section{Dear Colleagues,}

I believe it is rather safe to say that 2021 flew faster than expected. I am not sure why and how. I personally feel that if I were asked to 'evaluate me' during this past year, I wouldn't be able to pin-point exactly what I have done and accomplished. Is it the pandemic? Is it the uncertainty that still hangs above our heads? Is it that what was known as 'normal' does not exist anymore? Maybe all the above? Regardless, 2021 is over. Thus, we only have one option: move on, move forward, learn from the past, make everything better starting in 2022. This is easier said than done, but there is no alternative. I strongly believe in what I have stated.

With respect to our journal, looking back, we have had a solid year JINT-wise: We have completed the transition to CAP; we process the submitted papers much faster - on average within 24 to $48 \mathrm{~h}$ once assigned to me; we have established a 'due process' to check submitted papers for possible 'submission duplication' with the help of the authors; we are 'stricter' when it comes to percentage of overlap with previously published work - overall overlap should be about $20 \%$ with clear statements of originality and novelty; we have enforced the three review requirement per paper (note that on occasion, when two reviews are very detailed and consistent, to shorten the review cycle, we still make a recommendation); we have reduced the time from submission to first decision. These steps are not 'one-time' steps. We will continue to improve and take corrective actions when needed.

We look forward to a better and stronger 2022 year. We thank you for your support and contributions, all of you, the authors, the reviewers, the handling editors and members of the editorial board. On a personal note, I want to thank the Springer team, Nathalie, Anneke, Marie Veth, Jill (who moved on) and Karen who joined us, for their professionalism and collegiality; they are the ones who have made my editorial life easier.

Last, but not least, I wish you wholeheartedly Merry Christmas and a Happy New Year, with health, happiness, and prosperity.

Enjoy the issue.

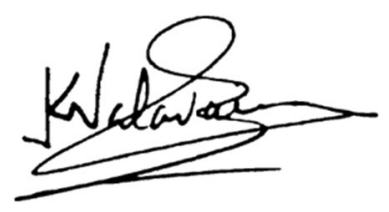

Kimon P. Valavanis

Editor-in-Chief

Publisher's Note Springer Nature remains neutral with regard to jurisdictional claims in published maps and institutional affiliations.

Kimon P. Valavanis

Kimon.Valavanis@du.edu

1 D. F. Ritchie School of Engineering and Computer Science, University of Denver, Denver, CO 80208, USA 